\title{
Iconografía urbana, memoria e identidad de las ciudades portuarias del Norte y Noroeste de España
}

\author{
Carla Fernández Martínez* \\ Universidad de Santiago de Compostela \\ Departamento de Historia del Arte \\ carla.fernandez@usc.es
}

\section{RESUMEN}

Entre las diversas fuentes de las que disponemos para el conocimiento de la ciudad destaca el repertorio de documentos gráficos que nos permiten observar cómo era su urbanismo en una época determinada, pero también cuál era la propia concepción que de ella se tenía.

Precisamente, este artículo pretende exponer una investigación que estudia cómo se fue elaborando la imagen artística de la ciudad portuaria del norte y noroeste de España. Desde la Edad Moderna hasta el siglo XIX, los retratos de sus paisajes urbanos, además de plasmar sus transformaciones físicas, sufrieron variaciones dependiendo de los mensajes que debían inmortalizar o los objetivos que perseguían.

En síntesis, se mostrará una metodología que permite entender la utilidad de los testimonios plásticos para el estudio de la evolución urbana y para conocer formas y modos de vida del pasado, concepciones culturales y distintas percepciones de una misma realidad.

Palabras clave: iconografía urbana; ciudad portuaria; paisaje urbano; percepción visual.

\section{Urban Iconography, Memory and Identity of the Port Cities of the North and Northwest of Spain}

\begin{abstract}
Among the several sources we have at our disposal for our knowledge of them stands out the compendium of graphic documents, which allows us to observe how it was their urbanism at a certain epoch, and also which the very conception.

Precisely, this article aims to expound a research which studies how the artistic image of the port cities in the North and Northwest of Spain was made and propagated. From the Modern Age to the nineteenth century, the portraits of their urban landscape, besides representing their physical transformations, were altered depending on the messages they were intended to immortalize or the objectives pursued.

In summary, it will expound a methodology which allows to understand the utility of the plastic testimonies for the study of the urban evolution and to know ways and lifestyles from the past, cultural conceptions and different perceptions of the same reality.
\end{abstract}

Key words: urban iconography; port city; townscape; visual perception.

\footnotetext{
* Investigadora del Grupo Iacobus (GI 1907) de la Universidad de Santiago de Compostela, vinculado a los proyectos: «Encuentros, intercambios y presencias en Galicia entre los siglos XVI y XX» (HAR2011-22899), del «Programa de Consolidación e Estructuración de Unidades de Investigación Competitivas» (GRC2013036) y del «Programa de Consolidación e Estructuración. Redes» (R2014/024).
} 


\section{Introducción metodológica. La utilidad de la iconografía urbana en el estudio de la ciudad}

Este trabajo tiene como objeto el análisis de la iconografía de las ciudades portuarias del Norte y Noroeste de España ${ }^{1}$. Por ello, resulta pertinente comenzar precisando qué entendemos por iconografía urbana, partiendo de la definición aportada por De Seta y el Centro Interdipartamentale sulla Iconografia della città Europea, dependiente de la Universidad Federico II de Nápoles ${ }^{1}$. Según los investigadores italianos, se trata del conjunto de imágenes de la ciudad que nos informan sobre su arquitectura, su espacio urbanizado y su gestión, al tiempo que se presentan como una ventana para estudiar el mundo de las ideas y su relación con la ciencia, el arte y la percepción visual. Engloba, por tanto, desde la cartografía hasta las vistas y perfiles que ofrecen una imagen global de la urbe o de alguna de sus partes².

En este caso, veremos cómo se elaboró y difundió la imagen artística de las ciudades portuarias del norte y noroeste de España a través de las series de vistas en las que figuraron gran parte de ellas, las publicaciones periódicas ilustradas que incluyeron grabados y estampas de sus puertos y barrios marineros y las visiones realizadas en época contemporánea ${ }^{3}$. Aunque su representación nació vinculada a una función estratégica y propagandística, pronto las vistas descriptivas dieron lugar a interpretaciones personales y subjetivas, sobre todo a partir de la segunda mitad del siglo XIX. Fue entonces cuando los artistas comenzaron a plasmar en su obra diferentes concepciones de una misma ciudad, ciudades alternativas y superpuestas que confirman el hecho de que cada persona construye su propia percepción que puede ser incluso diferente al espacio real.

\section{El interés por la ciudad portuaria}

Si hiciésemos un breve repaso histórico, constaríamos que los puertos y las fachadas marítimas fueron motivo de representación desde época remota. A algunos les cautivó el mundo del viaje, otros se sintieron seducidos por la navegación y por los avatares de los hombres en sus aventuras marítimas y un tercer grupo se interesó por sus aspectos costumbristas. $\mathrm{Y}$ es que los puertos siempre han sido lugares de idas $\mathrm{y}$ venidas, de encuentros y desencuentros, de guerras y exploraciones, de ahí la atracción que despertaron entre los viajeros y los soberanos preocupados por su defensa y protección.

\footnotetext{
1 Para mayor información sobre sus investigaciones, puede resultar ilustrativo consultar: http://www. iconografiaurbana.it/(21-01-2012). Entre sus múltiples publicaciones, cabe destacar: SETA, Cesare de, Città d'Europa. Iconografia e vedutismo dal XV al XIX secolo, Napoli, Electa, 2004; Idem, Tra Oriente e Occidente: città e iconografía dal XV al XIX secolo, Napoli, Electa, 2004.

2 En el ámbito español es necesario aludir a los estudios de Marías y Pereda: MARÍAS FRANCO, Fernando y PEREDA ESPESO, Felipe, El Atlas del rey Planeta: "La Descripción de España y costas y puertos de sus reinos", Hondarribia, Nerea, 2002.

3 Conviene señalar que esta metodología fue presentada en el I Encuentro Asturiano de Jóvenes Investigadores de Historia del Arte, organizado por la Universidad de Oviedo el 8 y 9 de marzo.
} 
Por otro lado, esta tipología urbana ha sido objeto de numerosos estudios que han ido formulando diversas definiciones para precisar sus rasgos más propios ${ }^{4}$. De lo que no cabe duda es de su antigüedad, toda vez que si los mares y los ríos fueron las primeras vías de comunicación utilizadas por los hombres, los asentamientos humanos más remotos se situaron en sus inmediaciones, siendo el puerto el motor de su crecimiento. Desde entonces, sus relaciones con la urbe fueron múltiples y de diversa índole: económica, socio-cultural y, por supuesto, urbanística. Es cierto que no existe un modelo portuario único en el territorio atlántico, como se constata en el norte y noroeste peninsular. Se trata de núcleos que se desarrollaron según esquemas y en momentos diferentes. Sin embargo, comparten ciertas características, precisamente por pertenecer a un mismo espacio geográfico.

\section{Iconografía urbana en la Edad Moderna. De Civitates Orbis Terrarum a las vistas de Mariano Sánchez}

A partir del Renacimiento el gusto por las vistas urbanas se difundió por el continente. Papas, nobles y soberanos comenzaron a encargar a numerosos artistas genuinos retratos de la ciudad y del territorio que cristalizaban su orgullo personal y, al mismo tiempo, materializaban la consistencia física e ideológica de la urbe. Desde entonces y hasta bien avanzada la Edad Moderna, su representación constituyó un medio eficaz de propaganda política, que también permitía conocer las peculiaridades de las poblaciones, el estado de las fortificaciones y construcciones y las características geográficas de cada emplazamiento. En este contexto, nació la iconografía urbana de las ciudades costeras del norte y noroeste de España. Fue entonces cuando el Arte y la Ciencia se dieron la mano para plasmar el aspecto de las poblaciones y su relación con la orografía del terreno. Se trató de una nueva actitud cognitiva, en la que participaron arquitectos, pintores, ingenieros, científicos y monarcas ${ }^{5}$, y favoreció el perfeccionamiento de la pintura en Italia y de la cartografía en los Países Bajos, dando lugar a numerosas series de vistas y atlas geográficos, tras el redescubrimiento de la obra Ptolomeo $^{2}$, base para la construcción de los mapas terrestres y las cartas náuticas.

En España, fue Felipe II el iniciador de esta campaña y fruto de su fascinación por la geografía y las vistas urbanas conservamos magníficas imágenes. Este monarca tuvo un gran interés por conocer los territorios de la Corona y en 1559 encargó a Jacob Van Deventer la realización de doscientas cincuenta plantas de las ciudades de los antiguos Países Bajos ${ }^{6}$. Unos años después, encomendó a Anton van den Wyn-

4 MARTÍNEZ SHAW, Carlos, "La ciudad y el mar. La ciudad marítima y sus funciones en el Antiguo Régimen”, en Manuscrits, $\mathrm{n}^{\circ} 15,1996$, pp. 257-278. SAUPIN, Gay, Villes Atlantiques dans L'Europe Occidentale du Moyeu âge au XX siècle, Rennes, Presses Universitaries, 2006, pp. 9-41. 37.

5 BESSE, Jean-Marc, Voir la terre, six essais sur le paysage et la géographie, Arles, Actes Sud, 2000, p.

6 Para mayor información sobre la figura de van Deventer: BRACKE, William, "Jacob van Deventer e l'atlante di città dei Paesi Bassi", en SETA, Cesare de (coord.) Le città dei cartografi. Studi e ricerca di storia urbana, Napoli, Electa, 2008, pp. 38-48. 
gaerde una colección sobre algunas urbes españolas ${ }^{7}$; la serie satisfacía su deseo de poseer visualmente las principales poblaciones del Reino y fue ideada como estudio preparatorio para la decoración de los palacios reales. El artista incluyó extraordinarios retratos de algunos puertos, pero falleció antes de poder concluir su periplo por el Norte. De este modo, tendremos que esperar unos años para encontrar algún testimonio del Norte. Se trata de las vistas de Santander, Bilbao y San Sebastián del Civitates Orbis Terrarum, obra de Franz Hogemberg y George Braun, editada en Colonia desde el 1572 hasta el $1618^{8}$. Esta magna obra, compuesta por seis volúmenes, fue la más completa del momento. Probablemente, la idea de publicar una recopilación de vistas de ciudades surgió en torno a 1567 en Amberes. Contemporánea a la de Wyngaerde y al Teatrum Orbis Terrarum de Abraham Ortelio, como ellas pretendía dar a conocer el mundo o una parte del mismo. En efecto, según Braun, su finalidad era que el lector, sentado cómodamente en su butaca, aprendiese a través de las imágenes cosas acerca de otros pueblos y países, supliendo así lo que solo con largos, penosos y costosos viajes podría descubrir ${ }^{9}$. Desde 1572 y hasta 1617 se publicaron los seis volúmenes integrados por más de quinientas ciudades, en su mayor parte de Europa. En el caso español, contaron con la ayuda de George Hoefnagel, un dibujante excelente que realizó los bocetos entre 1563 y 1567; un siglo después, en 1657, Johannes Janssonius compró las planchas para publicarlas en un solo volumen: Theatrum Hispaniae Urbes ${ }^{10}$.

Para representarlas no siguieron un mismo criterio compositivo y, aunque parten de un punto de vista elevado e imaginario, en algunos casos nos encontramos con vistas a vuelo de pájaro y en otros, con panorámicas, tipología a la que se adscriben la mayor parte de las urbes hispanas ${ }^{11}$. La ciudad se muestra en un segundo plano, pero dominando el territorio y el paisaje circundante; de su morfología destacan aquellos edificios más significativos, mientras que el caserío aparece de manera homogénea. Además, cada lámina se acompañaba de motivos alusivos a la vida cotidiana, a sus ciudadanos, indumentarias y costumbres ${ }^{12}$.

7 Las vistas de Van der Wyngaerde han sido estudiadas detenidamente, entre otros por: GALERA I MONEGAL, Montserrat, Anton van den Wingaerde, pintor de ciudades y de hechos de armas en la Europa del Quinientos, Barcelona, Generalitat de Catalunya, Institut Cartogràfic de Catalanya, Fundación Carlos de Amberes, 1998; HAVERKAMP-BEGEMANN, Egbert, "Las vistas de España de Anton Van den Wyngaerde", en KAGAN, Richard (coord.), Ciudades del siglo de oro. Las vistas urbanas de Anton Van der Wyngaerde, Madrid, Visor, 1986, pp. 54-67.

8 SAZATORNIL RUIZ, Luis: "Entre la vela y el vapor. La imagen artística de las ciudades portuarias cantábricas”, en FORTEA PÉREZ, José Ignacio (coord.), La ciudad portuaria atlántica en la historia: siglos $X V$ al XIX, Santander, Autoridad Portuaria de Santander, 2006, p. 90.

9 Sobre las intenciones de la obra, véase: SANTIAGO PAEZ, Elena, Teatro de las más ilustres ciudades de España y Portugal, Barcelona, Lunwerg, 1996.

10 Ibid.

11 Sobre la clasificación tipológica de las vistas urbanas, véase: SETA, Cesare de, "La clasificazione tipológica dell'iconografia urbana", en SETA, Cesare de (coord.), L'Europa Moderana. Cartografia urbana e vedutismo, Napoli, Electa, 2000, pp. 28-32.

12 Para profundizar en la evolución de las vistas de Santander, véase: SAZATORNIL RUIZ, Luis, ALONSO RUIZ, Begoña, Vistas y visiones. Imagen artística de Santander y su puerto, 1575-1950, Santander, Navalia Visual, 1995. Sobre Bilbao: ZUGAZA MIRANDA, Miguel, La Ría: Imagen y visión de un paisaje mercantil, Bilbao, Museo de Bellas Artes, 1993. 
Entre las diecinueve ciudades españolas se encontraban las vistas de Bilbao (fig. 1), San Sebastián y Santander. Su inclusión se relaciona con la importancia que estaban comenzado adquirir y significaba, como ha apuntado Sazatornil Ruiz, pasar de ser oscuras villas costeras a convertirse simbólicamente en miembros del selecto grupo de las ciudades más importantes de todo el Orbe ${ }^{13}$.

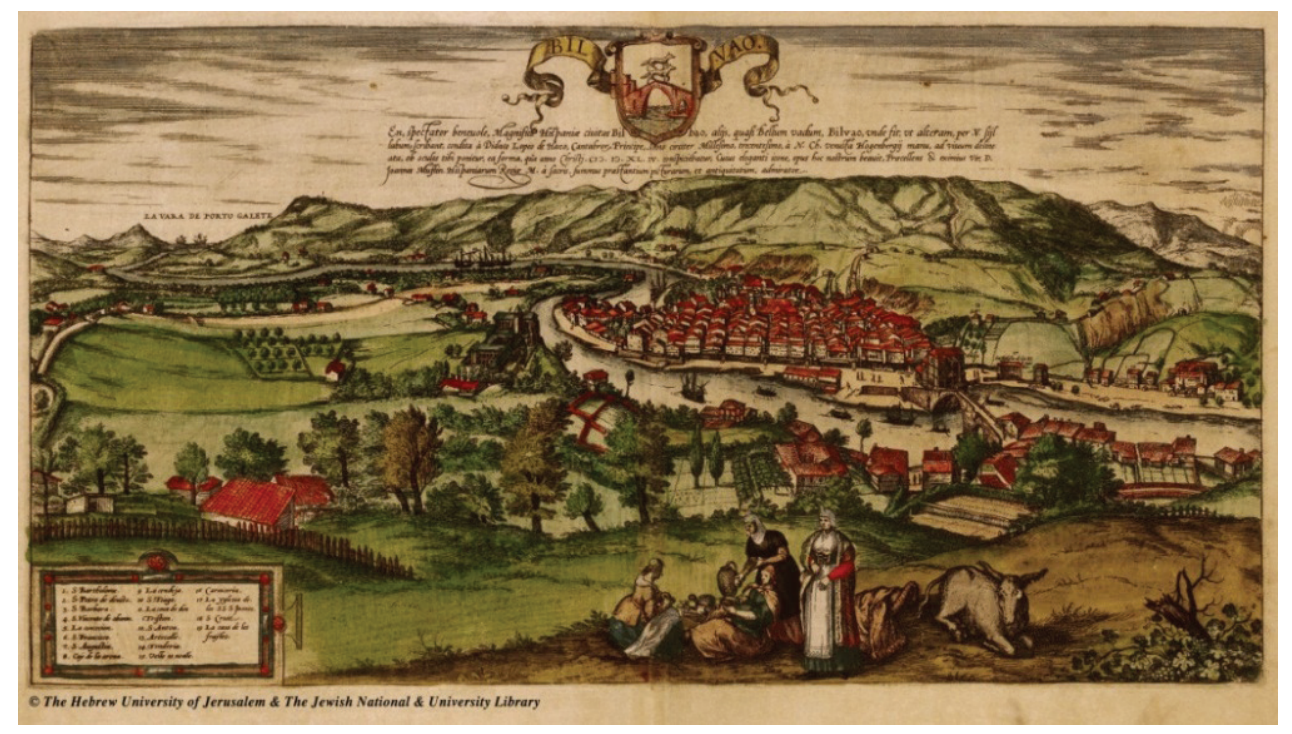

Fig. 1. Bilbao. Civitates Orbis Terrarum. Hogemberg-Braun.

Ciertamente, fueron los únicos ejemplos del litoral cantábrico que tuvieron el privilegio de figurar entre los más relevantes del mundo. La serie gozó de un gran éxito $\mathrm{y}$ en las centurias sucesivas se reeditó y tradujo a un gran número de idiomas ${ }^{14}$. Sus láminas se convirtieron en imágenes tópicas, promoviendo una visión estática de la ciudad y del puerto que sirvió de motivo e inspiración hasta bien entrado el siglo $\mathrm{XIX}^{15}$.

Unas décadas después, en 1634, apareció una colección que había sido encargada por la monarquía y que incluyó un buen número de imágenes alusivas a las ciudades y villas de la franja atlántica, especialmente de sus plazas fuertes. Se trata de la Descripción de España y de las costas y puertos de sus reinos, comisionada por Felipe

13 SAZATORNIL RUIZ, Luis (2006), op. cit., p. 90.

14 Entre las copias de Civitates destacan las de: VALLEGIO, Francesco, Raccolata di le più illustri citti di tutto il mondo, Venezia, 1572; VAN DER AA, Pieter, Galerie agreable du monde, 1701; ÁLVAREZ DE COLMENARES, Juan, Les délices de L'Espagne \& du Portugal, 1707.

15 SAZATORNIL RUIZ, Luis y ALONSO RUIZ, Begoña (1995), op. cit. 
IV y ejecutada por el cosmógrafo portugués Pedro Texeira ${ }^{16}$. La obra ha sido rigurosamente estudiada por Marías y Pereda, así que partiremos de sus consideraciones ${ }^{17}$.

Felipe IV había accedido al trono en 1621, en un momento delicado políticamente -guerra con los Países Bajos, hostilidad con Francia...-, que requería medidas para la salvaguardia de las costas peninsulares; de ahí que pronto comprendiese la necesidad de tener un mayor conocimiento del litoral español, motivo que le llevó a promover y acometer la mayor obra cartográfica del siglo XVII ${ }^{18}$. Texeira debía presentar un corpus iconográfico que permitiese apreciar de forma precisa la posición de cada puerto para facilitar la navegación y calcular su distancia con respecto a las fortificaciones, faros, monumentos más destacados y accidentes geográficos. El resultado fue la creación de un atlas detallado, integrado por ricas descripciones y tres tipos de documentos gráficos: los dibujos de las poblaciones del litoral, los mapas de las diversas regiones que facilitan su localización y, por último, uno de la Península y otro del Orbe. Lo que nos interesa son sus dibujos topográficos, tomados desde un punto imaginario y elevado, más si cabe que los de Braun, como si nos situásemos por encima del mar. Esta perspectiva le permitió recrearse en la plasmación de las peculiaridades geográficas y estratégicas, mientras que la traza urbana está solo esbozada, sobresaliendo algunos de los edificios más emblemáticos. Por otro lado, concedió un gran protagonismo al mar, deteniéndose en su plasmación y ofreciendo información sobre el oleaje y las corrientes (fig. 2).

Tendremos que esperar hasta 1786 para encontrar la siguiente serie sobre nuestros puertos. Me refiero a las vistas realizadas por Luis Paret y Alcázar, a petición de Carlos III a partir del 1786, y las de Mariano Sánchez, encargadas por Carlos IV en $1792^{19}$. El gusto por las vistas de puertos se había difundido en Europa, tras una producción francesa patrocinada por Luis XV y realizada por Claude-Joseph Vernet $^{20}$. Estos lienzos gozaron de un gran éxito y se divulgaron en grabados por todo el continente, despertando el deseo de nuestros monarcas de poseer una serie semejante.

16 Se había considerado que esta obra había desaparecido, pero se encuentra depositada en la Hofbibliothek de Viena (Codez Miniatus 46). Texeira realizó también un plano de Madrid bajo el título de Topographia de la Villa de Madrid; otros dibujos de las poblaciones vascas y el Compedium Geographicum dedicado al primer marqués de Leganés que contiene un mapa del Orbe, otro de España y seis más de la costa cantábrica y de Galicia.

17 MARÍAS FRANCO, Fernando y PEREDA ESPESO, Felipe (2002), op. cit.; MARÍAS FRANCO, Fernando y PEREDA ESPESP, Felipe, "De la cartografía a lo corografía: Pedro Texeira en la España del Seiscientos", en Ería, no 64-65, 2004, pp. 129-157.

18 Para mayor información sobre el uso de la imagen por Felipe IV, vid. BROWN, Jonatthan y ELLIOT, John Hustable, Un palacio para el rey. El Buen Retiro y la corte de Felipe IV, Madrid, Taurus, 2003; KAGAN, Richard, "Imágenes y política en la corte de Felipe IV", en PALOS PEÑARROYA, Joan Lluís y CARRÓINVERNIZZI, Diana (coord.), La historia imaginada. Construcciones visuales del pasado en la Edad Moderna, Madrid, Centro de Estudios Europa Hispánica, 2008, pp. 101-119.

19 Mariano Sánchez comenzó a trabajar para Carlos III en 1781, momento en el que recibió el encargo de realizar una colección completa de todas las vistas de puertos y bahías de España e islas adyacentes, así como de sus arsenales; no obstante, fue ya bajo el mandato de Carlos IV cuando ejecutó las relativas a Galicia, Asturias y Santander.

20 INGERSOLL-SMOUSE, Florence, Joseph Vernet: peintre de marine, 1714-1789, Paris, Etienne Bignon, 1926. 


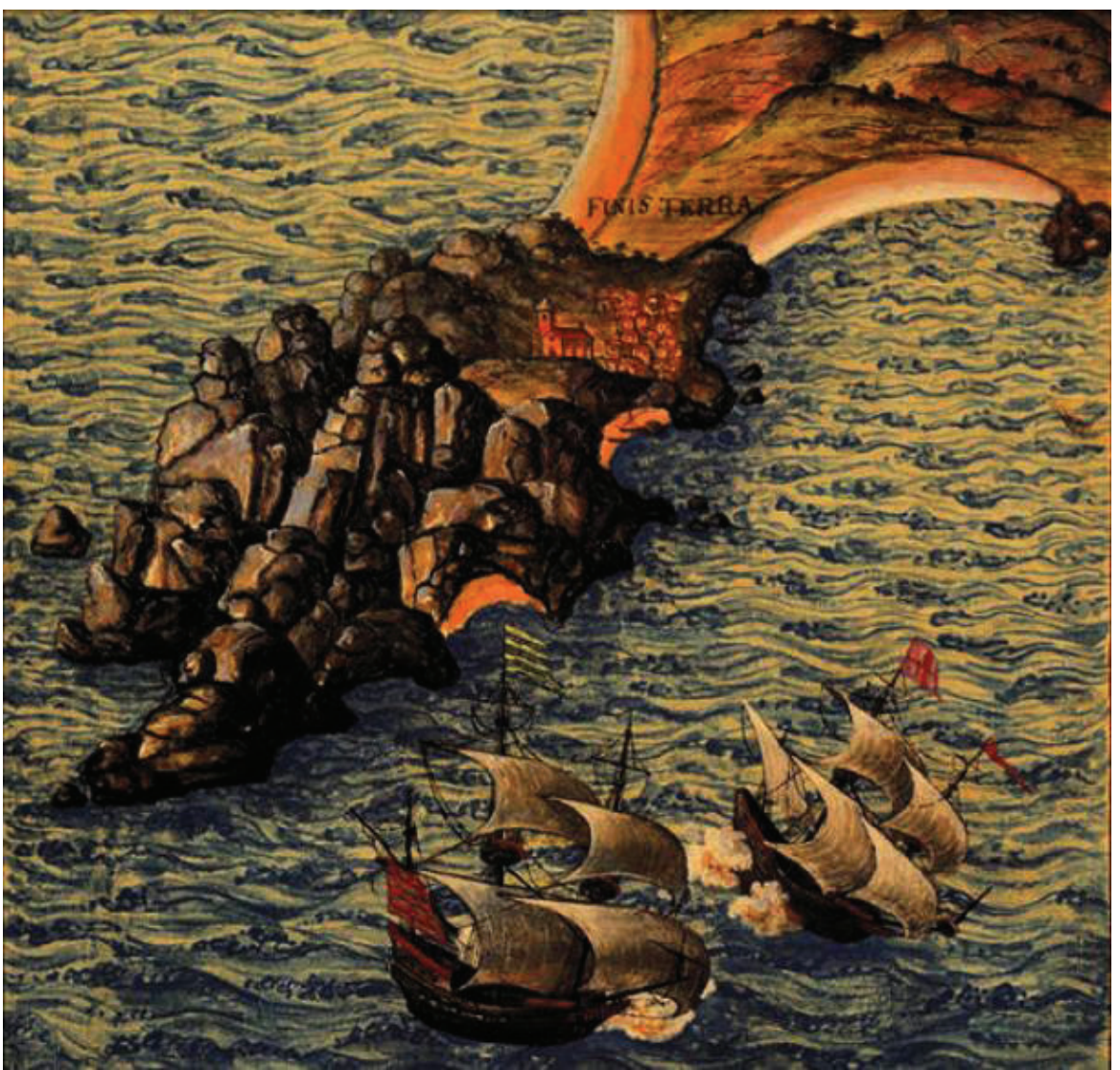

Fig. 2. Finisterre. Descripción de España y costas y puertos de su Reino. Pedro Texeira, 1634.

Luis Paret y Alcázar había estudiado en la Academia de Bellas Artes de San Fernando y en Roma, pensionado por el infante don Luis, con el que mantenía una estrecha relación ${ }^{21}$. Tras un incidente en la casa de su mecenas, fue desterrado a Puerto Rico $^{22}$. En 1778 se le conmutó la pena y se instaló en Bilbao, ciudad en la que se casó y vio nacer a sus dos hijas. Una vez allí, comenzó a interesarse por el tema marino y en 1783 pintó una vista del Arenal de Luchana y otra de Bermeo. El 4 de julio de 1786 recibió el encargo de Carlos III de realizar las vistas de los puertos, con la obligación de entregar dos obras al año. ${ }^{23} \mathrm{El}$ monarca quería contemplar y exponer en la Casita

21 Para mayor información sobre el pintor, véase: DELGADO MERCADO, Osiris, Luis Paret y Alcázar, pintor español, Madrid, Universidad de Puerto Rico, 1957.

22 VV.AA., Luis Paret y Alcázar, Vitoria, Servicio Central de Publicaciones del Gobierno Vasco, 1991, pp. 59-78.

23 El 4 de julio de 1786, Carlos III comisionó a Paret para pintar las vistas de los puertos cántabros. Debía entregar, al menos, dos obras al año con una remuneración anual de 15.000 reales. Véase: VV.AA. (1991), op.cit., pp. 92-95. 


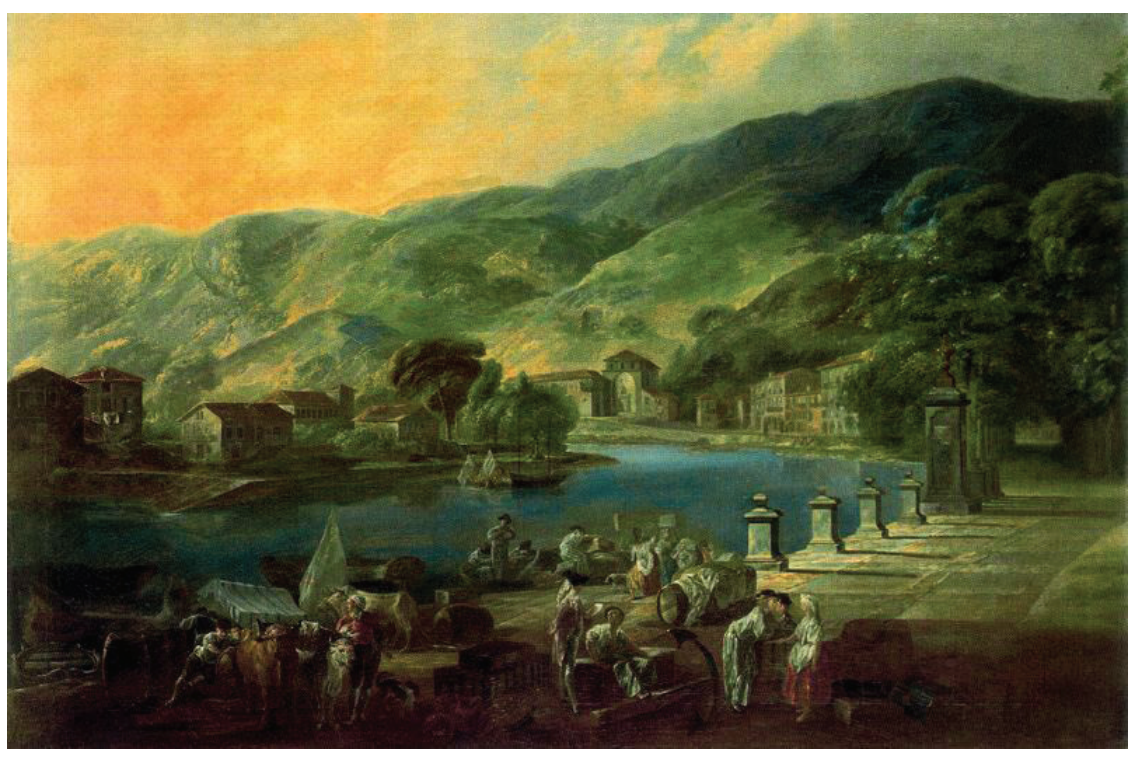

Fig. 3. Vista del Arenal de Bilbao. Luis Paret y Alcázar, 1783.

del Príncipe de El Escorial los puertos y marinas de su Reino, por lo que Paret los dotó de un efecto decorativo, acorde con su propio estilo ${ }^{24}$. De este modo, los concibió como paisajes compuestos con figuras en primer plano que centran la composición y justifican el fondo (fig. 3). Presentan escenas costumbristas con pescadores, estibadores, mujeres trabajando, caballeros, damiselas, clérigos, frailes y soldados en un ambiente tranquilo y relajado, donde el realismo remite a favor de una imagen placentera y sosegada, similar a la que Vernet dejó de los puertos francos.

En esos mismos años, Mariano Sánchez comenzó a cultivar también esta temáti$\mathrm{ca}^{25}$. Al igual que Paret, se había formado en la Academia de San Fernando ${ }^{26}$ y pronto destacó por sus cualidades de miniaturista, trabajando al servicio del Rey de Portugal ${ }^{27}$. Fue en 1781 cuando el futuro Carlos IV le encargó una colección completa de todas las vistas, puertos y bahías de España e islas y de sus arsenales ${ }^{28}$. Aunque

24 GAYANUÑO, Juan Antonio, "Luis Paret y Alcázar", en Boletín de la Sociedad Española de Excursiones, $\mathrm{n}^{\circ} 16,1952$, pp. 87-153.

25 Las referencias bibliográficas sobre el pintor se encuentran recogidas en diversos estudios, aunque cabe destacar: ORELLANA MOCHOLÍ, Marcos Antonio, Biografia pictórica valentina, Valencia, Editorial Xavier de Salas, 1967, pp. 441 y ss.

26 PARDO CANALÍS, Enrique, Los registros de Matrícula de la Academia de San Fernando de 1752 a 1815, Madrid, Instituto Diego Velázquez, 1967, p. 104.

27 ESPINÓS DÍAZ, Adela, "Mariano Sánchez (1840-1822): Paisajista al servicio de la Corte", en El Arte en tiempos de Carlos III (Madrid, 1988), Madrid, Alpuerta, 1989, p.324.

28 El conjunto de lienzos ha sido estudiado por: ALBA PAGÁN, Ester, "La pintura y los pintores valencianos en las "casitas" del Real Sitio de San Lorenzo del Escorial: Mariano Salvador Maella, Benito Espinós, Miguel Parra, José López Enguídanos y Mariano Sánchez”, en CAMPOS Y FERNÁNDEZ DE SEVILLA, Francisco Javier, El Monasterio del Escorial y la pintura, Actas del Simposium, (El Escorial, 15 de noviembre de 2001), 


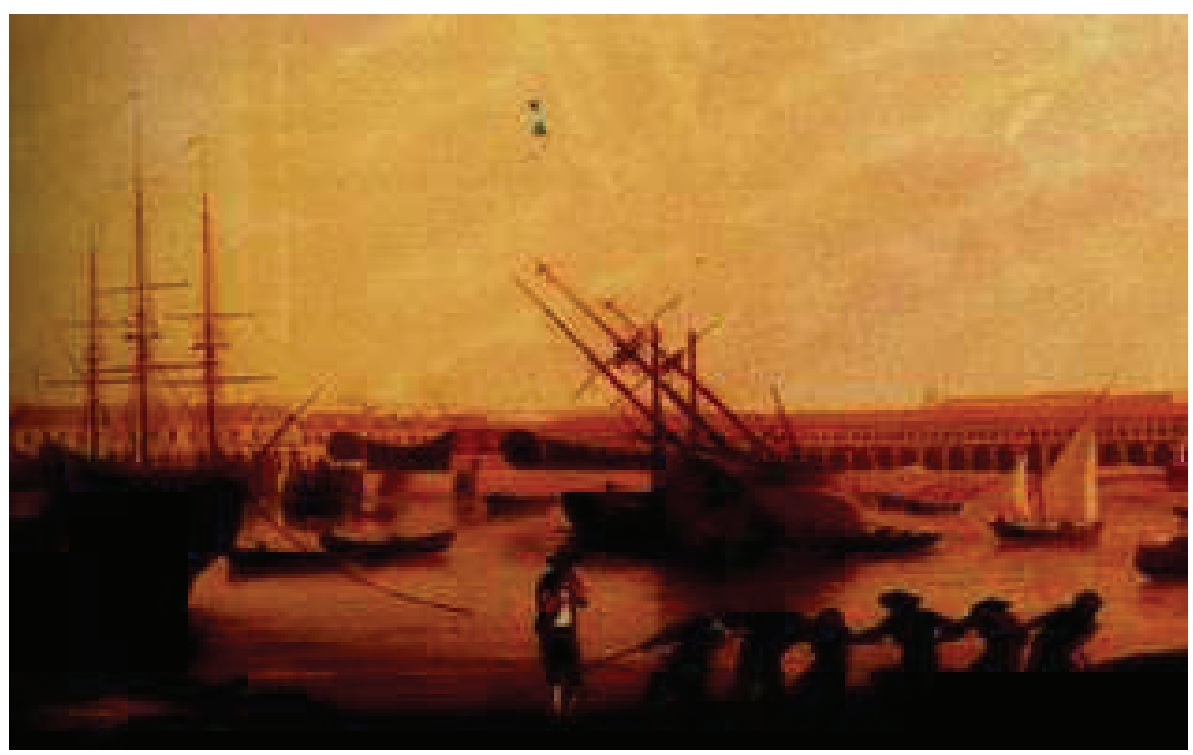

Fig. 4. Vista del Arsenal de Ferrol. Mariano R. Sánchez, 1895.

el objetivo era dejar constancia de los logros producidos por las reformas, también respondían al afán descriptivo y de conocimiento propio de la Ilustración ${ }^{29}$. La obra se inició en 1781; el artista se trasladó a Cádiz para comenzar las vistas de Andalucía, pasando por el norte en $1792^{30}$. Si comparamos su obra (fig. 4) con la de su predecesor, comprobamos que abandonó esa imagen idealizada y placentera, para mostrar la pujante situación de las ciudades y villas del litoral, favorecidas por las iniciativas regias.

No fueron estas las únicas series sobre los puertos españoles; también se realizaron otras con la intención de divulgarse entre un público más amplio. Alexander Jean Noel recorrió la Península junto con el grabador François Allix para elaborar varios grabados de tema marítimo; el proyecto no pudo concluirse y solo se efectuaron dos entregas con vistas de Lisboa, Cádiz y Cartagena. Por otro lado, Pedro Grolliez fue el responsable de unos dibujos como base para otra serie de grabados. De los originales

San Lorenzo del Escorial, Ediciones Escurialense, 2001, pp. 759-784; BARRENO SEVILLANO, María Luisa, "Vistas de puertos. Cuadros de Marino Sánchez pintor al servicio de Carlos IV", en Reales Sitios, n 51, 1977, pp. 37-44: ESPINÓS DÍAZ, Adela (1989), op. cit.; JUNQUERA MATO, Juan José, La decoración y el mobiliario de los palacios de Carlos IV, Madrid, Organización Sala Editorial, 1979; MANO, José Manuel, "Mariano Sánchez y las colecciones de vistas de puertos en la España de finales del siglo VIII", en I Congreso Internacional de Pintura Española del siglo XVIII (Marbella 15 al 18 de abril de 1998), Marbella, Fundación Museo del Grabado Español, pp. 351-369; MORALES MARÍN, José Luis, Pintura en España 1750-1808, Madrid, Cátedra, 1994. pp. 245-246; SAZATORNIL RUIZ, Luis (2006), op.cit., pp. 102-103.

29 En este sentido, es pertinente señalar que paralelamente a esta serie se encomendó al pintor Luis Meléndez otra sobre los productos del territorio español.

30 La documentación relativa a este trabajo se encuentra en el expediente personal del pintor en el Archivo del Palacio Real. Caja 961/47. 
tan solo se conocen los relativos a la vista de la ría de Vigo, Bayona, Avilés, Ribadeo y Ferrol $^{31}$, pero la obra se componía de treinta ${ }^{32}$.

Lo interesante de estas colecciones es que constatan cómo las vistas de nuestros puertos fueron utilizadas por la monarquía para expresar su poderío y grandeza. Ciertamente, aunque la iconografía urbana norteña nació vinculada al anhelo por conocer el mundo, los soberanos pronto comprendieron que la representación de sus dominios, al igual que la de sus victorias, era una forma de exaltar su figura y transmitirla al futuro.

\section{Del grabado informativo a las visiones finiseculares}

A partir del XIX se produjo una mayor variedad de testimonios y los artistas comenzaron a decantarse por visiones personales y evocadoras, en las que había cabida para retratar cualquiera de los elementos que configuran ese carácter variopinto de los puertos. Al mismo tiempo, la prensa ilustrada inauguró un nuevo tipo de imagen concebida como relato de actualidad. La relevancia de sus estampas y grabados reside en que fueron el principal medio de difusión de informaciones visuales. ${ }^{33}$ Las ideas mentales podían ser reproducidas y transmitidas, permitiendo que el lector realizase un viaje imaginario sin salir de su casa. Eran un ornamento, una forma de recordar las particularidades de un lugar, pero continuaban determinando la percepción de la realidad urbana. La Ilustración. Periódico Universal, El Museo Universal (fig. 5), La Ilustración Española y Americana, La Ilustración Gallega y Asturiana, La Ilustración Cantábrica, etc., son algunos de los títulos que muestran el papel de la estampa y el grabado para difundir datos sobre nuestras ciudades portuarias ${ }^{34}$.

La diversidad de obras realizadas a caballo entre el siglo XIX y el XX, evidencian diferentes formas de reaccionar ante unas transformaciones que alteraron profundamente nuestras ciudades. Un buen número sufrieron importantes reformas urbanísticas, con ensanches y nuevas infraestructuras que afectaron a sus puertos, a sus comunicaciones y a su demografía. Gijón encabezaba el panorama asturiano, gracias a su desarrollo industrial ${ }^{35}$; tras la apertura de la Carretera Carbonera en 1842 y la instalación del ferrocarril Sama-Gijón en 1856, se convirtió en el principal puerto minero. Santander continuaba siendo el más importante del Cantábrico. Bilbao, quintu-

31 Para mayor información véase: CARRETE PARRONDO, Juan, "La real Calcografía de Madrid en la época de Goya”, en LAUFENTE FERRARI, Enrique y CARRETE PARRANDO, Juan (Coord.), La Real Calcografía de Madrid. Goya y sus contemporáneos, Madrid, Real Academia de Bellas Artes de San Fernando, 1984. pp. 42-43.

32 El autor declaraba que: "enemigo de la ociosidad, espero con ansia nuevas órdenes, sea ara seguir el mismo trabajo en el interior del Reyno, sea por cualquier otra comisión". Archivo Histórico Nacional, Consejos, II.277/32.

33 Para mayor información vid.: RIEGO AMÉZAGA, Bernardo, La construcción de la realidad a través de la fotografía y el grabado en la España del siglo XIX, Santander, Servicio de Publicaciones de la Universidad de Cantabria, 2001.

34 Ibid.

35 Para mayor información, vid. ALVARGONZÁLEZ RODRÍGUEZ, Ramón: Gijón: industrialización y crecimiento urbano, Salinas, Ayalga, 1977. 


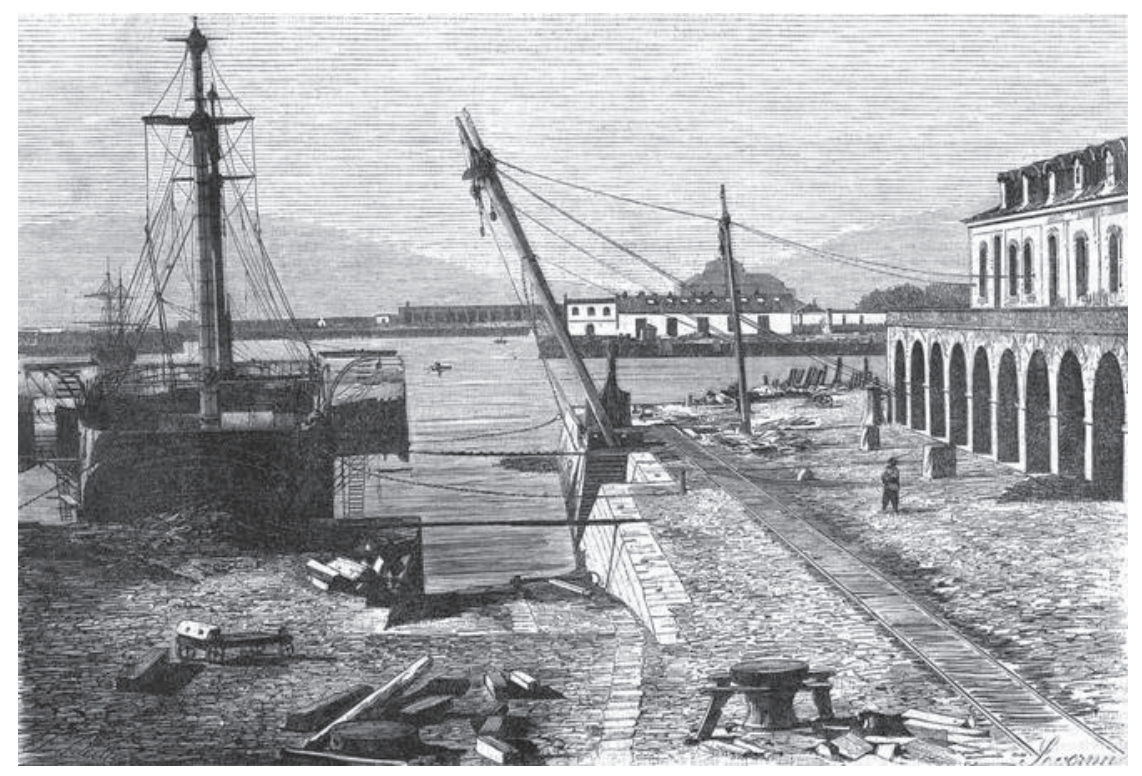

Fig. 5. "Vista del Arsenal del Ferrol”, en El Museo Universal, (30-09-1858), p. 141.

plicó su actividad portuaria, abriéndose al mar con el proyecto de Evaristo Churruca al frente de la Junta de Obras del Puerto ${ }^{36}$. En Galicia A Coruña destacaba por su modernidad y Ferrol seguía siendo el símbolo de la Armada ${ }^{37}$. Además, fue en nuestro litoral donde se inauguró un fenómeno propio del siglo XIX: el del veraneo ${ }^{38}$. Uno de los primeros focos de atracción fue la playa; la estancia en la costa se comenzó a asimilar a la buena salud y se crearon numerosos baños de agua salada. Esta nueva forma de vida estival cautivó a los artistas, propiciando la creación de numerosos lienzos dedicados al paisaje costero.

Ya cercano el fin de siglo, los pintores locales tomaron el relevo y nos dejaron imágenes evocadoras, abandonando la vista descriptiva y decantándose por la interpretación subjetiva ${ }^{39}$. Algunos se inclinaron por rechazar los cambios y las transformaciones de las urbes, mientras que otros exaltaron su modernidad, incorporando en sus lienzos la nueva imagen de los puertos con sus fábricas, ferrocarriles y nuevas infraestructuras. Eran el reflejo de las tensiones entre la nostalgia y el progreso características del convulso fin de siglo y que se constata, por ejemplo, en la obra de dos

36 SERRANO ABAD, Susana, "Paisaje e industria en el Bilbao del despegue (1860-1930)", en Historia Contemporánea, $\mathrm{n}^{\circ} 24,2002$, pp. 223-243.

37 BONET CORREA, Antonio, "Las ciudades gallegas en el siglo XIX", en Arte y ciudad. Ámbitos medieval, moderno y contemporáneo, Santiago de Compostela, Fundación Caixa Galicia, 2000, pp. 179-200.

38 LITVAK, Lily, A la playa. El mar como tema de la modernidad en la pintura española, 1870-1936, Madrid, Fundación Mapfre Vida, 2001, pp. 13-63.

39 LITVAK, Lily, El tiempo de los trenes. El paisaje español en el arte y la literatura del realismo (18491918), Barcelona, Ediciones del Serbal, 1991. 


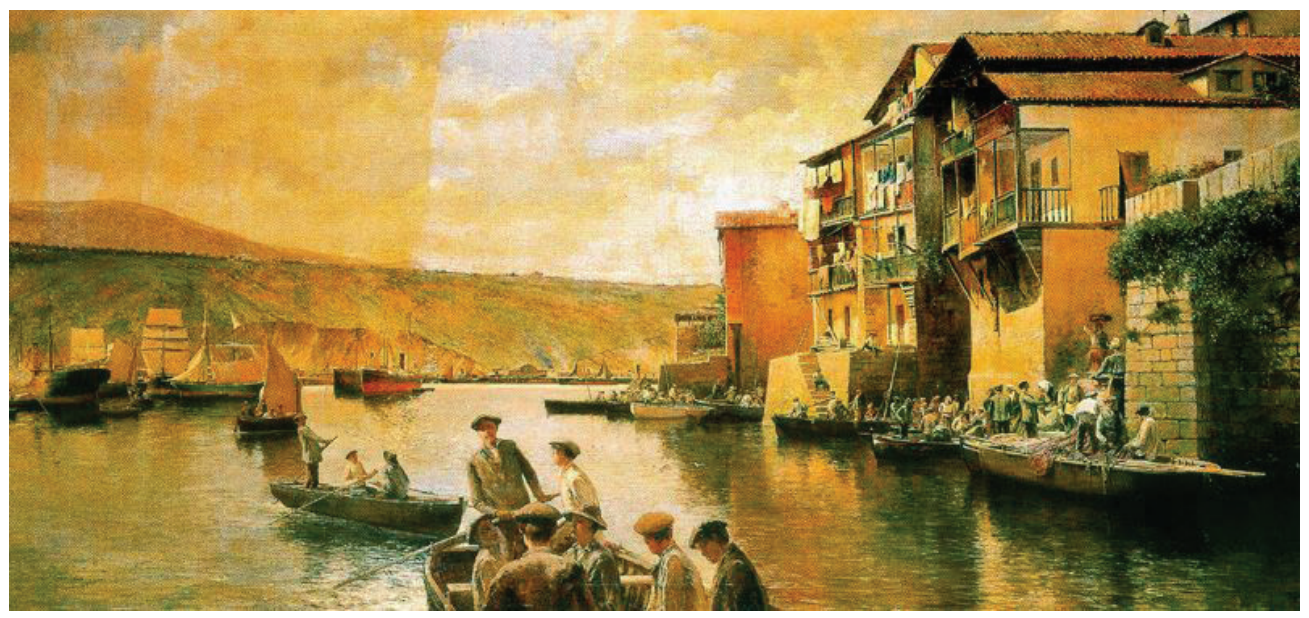

Fig. 6. Puerto de Pasajes. Tomás Campuzano y Aguirre, 1923.

destacados pintores dedicados al paisaje cantábrico como fueron el cántabro Tomás Campuzano y Aguirre (fig. 6) y el asturiano Juan Martínez Abades (fig. 7)

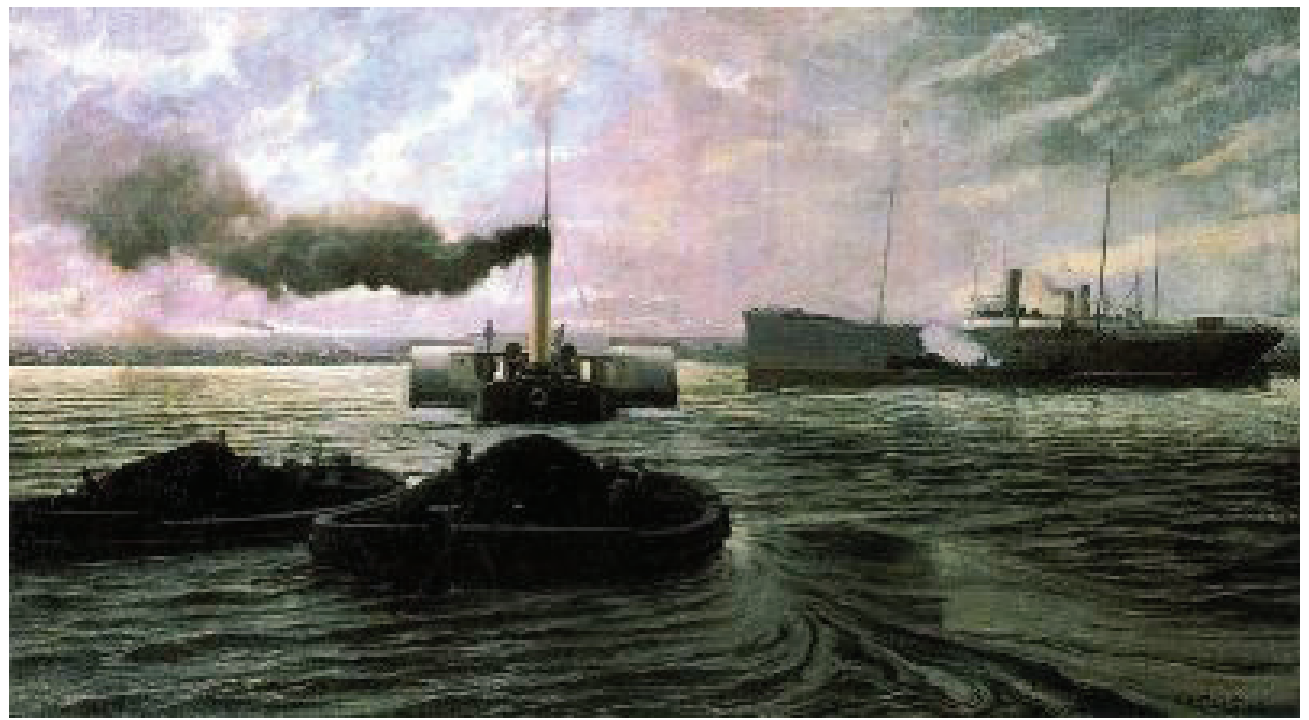

Fig. 7. Los carboneros. Juan Martínez y Abades, 1904.

40 RIVAS ANDRÉS, Victoriano, Juan Martínez Abades, Gijón, Ayuntamiento de Gijón, 1978; AA.VV., Tomás Campuzano y Aguirre (1855-1934), Santander, Fundación Marcelino Botín, 2000. 


\section{Nota final}

Sin duda alguna, la riqueza visual de las ciudades portuarias permitió la creación de esta amplia iconografía que se ha intentado esbozar. De esa vista objetiva y descriptiva, global y ordenada se pasó a otra personal e íntima, reflejo de los diversos elementos que intervienen en la ciudad. En realidad, estas últimas muestran múltiples formas de interpretar un mismo escenario urbano, al materializar diferentes modos de reaccionar ante un espacio y de ahí, que puedan concebirse como paisajes urbanos. Este término alude a un constructo mental, elaborado por el espectador a través de las sensaciones y percepciones producidas con la contemplación de un lugar. En este sentido, aunque algunos autores han trazado una línea evolutiva en la representación de la ciudad, cada imagen debe ser analizada de manera singular, como un testimonio único, íntimamente ligado a su contexto social, cultural y político.

Con todo, tras el repertorio de imágenes que la Historia nos ha legado sobre nuestros puertos, se esconde la mirada de su creador, intérprete, lector y transmisor de sentimientos, percepciones y concepciones que convierten a la ciudad un paisaje, capaz de despertar múltiples afectos y sentimientos. 